\title{
PERLINDUNGAN HAK REPRODUKSI PEREMPUAN UNTUK BER KBDIHUBUNGKAN DENGAN PROGRAM JAMINAN PERSALINAN (PERMENKES N0.2562/MENKES/PER/XII/2011)
}

\author{
Eldawaty, Agnes Widanti dan Yanti Fristikawati \\ eldawaty_phsatria@yahoo.com \\ Magister Hukum Kesehatan \\ Universitas Katolik Soegijapranata Semarang
}

\begin{abstract}
ABSTRAK
Dalam Undang-Undang Nomor 7 tahun 1984 disebutkan bahwa penghapusan diskriminasi dibidang pemeliharaan dan jaminan pelayanan kesehatan termasuk pelayanan KB. Melalui Undang-Undang ini memberikan landasan hukum tentang kepastian perlindungan terhadap hak reproduksi perempuan untuk bebas menentukan jumlah dan jarak kelahiran anak.

Salah satu upaya guna melindungi perempuan dari kematian akibat kehamilan, pemerintah melalui peraturan Menteri Kesehatan Nomor 2562/Menkes/Per/XII/2011 menyelenggarakan Jaminan Persalinan. Pada kebijakan operasional ini disebutkan bahwa penerima manfaat jaminan persalinan didorong untuk mengikuti program KB paska persalinan dengan membuat surat pernyataan. Kondisi ini menimbulkan pertanyaaan bagaimana perlindungan hak reproduksi perempuan dalam mengambil keputusan ber-KB, bagaimana hak reproduksi perempuan yang ingin menggunakan jaminan persalinan tapi tidak mau ber-KB dan apa kendala penerapan PERMENKES Nomor 2562/Menkes/PER/XII/2011 mengenai hak reproduksi perempuan dalam ber-KB.

Penelitian hukum ini menggunakan metode penelitian Deskriptif dengan pendekatan metode penelitian Yuridis Normatif ,sehingga jenis penelitian yang digunakan adalah studi kepustakaaan.Data yang dikumpulkan adalah data kualitatif dalam bentuk bahan pustaka,yakni bahan hukum primer,sekunder dan tersier.Sehubungan dengan data yang digunakan data kualitatif,maka akan dilakukan analisis kualitatif terhadap ketiga bahan hukum yang dikumpulkan,dan akan dirumuskan jawaban sementara berbentuk hipotesis kerja.

Kewajiban KB pasca persalinan dengan membuat surat pernyataan bertentangan dengan undang-undang. Perempuan tidak dapat menggunakan jaminan persalinan apabila tidak ingin ber-KB.Komunikasi,informasi dan edukasi yang kurang serta ketersediaan alat kontrasepsi yang tidak siap pakai merupakan kendala penerapan PERMENKES.Berdasarkan penelitian yang telah dilakukan,maka PERMENKES yang mengatur KB pasca persalinan perlu direvisi dengan mencantumkan kriteria-kriteria perempuan yang wajib untuk ber-KB guna melindungi perempuan dari kematian akibat kehamilan.
\end{abstract}

Kata Kunci : Perlindungan Hak Reproduksi perempuan, Keluarga Berencana, Jaminan Persalinan 


\section{LATAR BELAKANG}

Dewasa ini kesehatan reproduksi mendapat perhatian khusus secara global sejak diangkatnya isu dalam Konferensi Internasional tentang Kependudukan dan Pembangunan (International Conference on Populationand Development, ICPD), di Kairo, Mesir, pada tahun 1994. Dalam konferensi tersebut disepakatinya perubahan paradigma dalam pengelolaan masalah kependudukan dan pembangunan dari pendekatan pengendalian populasi dan penurunan fertilitas menjadi pendekatan yang terfokus pada kesehatan reproduksi serta upaya pemenuhan hak-hak reproduksi. ${ }^{1}$

Paradigma baru ini berpengaruh besar antara lain terhadap hak dan peran perempuan sebagai subyek dalam berkeluarga berencana-(KB). Perubahan pendekatan juga terjadi dalam penanganan kesehatan ibu dan anak, kesehatan reproduksi remaja, pencegahan dan penanggulangan Infeksi Menular Seksual (IMS) termasuk HIV/AIDS, serta kesehatan reproduksi usia lanjut, yang dibahas dalam konteks kesehatan dan hak reproduksi. Dengan paradigma baru ini diharapkan kestabilan pertumbuhan penduduk akan dapat dicapai dengan lebih baik. ${ }^{2}$

Sesuai dengan pembangunan global, dalam bidang kesehatan yang dideklarasikan sebagai Millennium Development Goals atau biasa disingkat MDGs merupakan usaha pemenuhan hak azasi dan kebebasan manusia, perdamaian, keamanan dan pembangunan.

Berdasarkan kesepakatan global (Millenium Develoment Goals/MDG's2000) pada tahun 2015, diharapkan angka kematian ibu menurun dari228 pada tahun 2007 menjadi 102 dan angka kematian bayi menurun dari 34 pada tahun 2007 menjadi 23.

Upaya penurunan AKI harus difokuskan pada penyebab langsung kematian ibu, yang terjadi $90 \%$ pada saat persalinan dan segera setelah persalinan yaitu perdarahan (28\%), eklamsia (24\%), infeksi (11\%), komplikasi pueperium $8 \%$, partus macet $5 \%$, abortus $5 \%$, trauma obstetric $5 \%$, emboli 3\%, dan lain-lain 11\% (SKRT 2001).

Kematian ibu juga diakibatkan oleh beberapa faktor resiko keterlambatan (Tiga Terlambat), di antaranya terlambat dalam pemeriksaan kehamilan (terlambat mengambil keputusan), terlambat dalam memperoleh pelayanan persalinan dari tenaga kesehatan, dan terlambat sampai di fasilitas kesehatan pada saat dalam keadaan emergensi.

Salah satu kendala penting untuk mengakses persalinan oleh tenaga kesehatan di fasilitas kesehatan adalah keterbatasan dan ketidak-tersediaan biaya sehingga diperlukan kebijakan terobosan untuk meningkatkan persalinan yang ditolong tenaga kesehatan di fasilitas kesehatan melalui kebijakan yang disebut Jaminan Persalinan yang diatur melalui permenkes no 631/menkes/per/III/2011. Jaminan persalinan mulai berlaku sejak 1 januari 2011 yang menjamin pembiayaan pelayanan kesehatan ibu meliputi pemeriksaan kehamilan, pertolongan persalinan, pelayanan nifas termasuk pelayanan KB paska persalinan dan pelayanan bayi baru lahir yang dilakukan oleh tenaga kesehatan difasilitas kesehatan.

Kebijakan operasional pengelolaan jaminan persalinan merupakan upaya untuk menjamin dan melindungi proses kehamilan, persalinan, paska persalinan, dan pelayanan KB paska salin serta komplikasi yang terkait dengan kehamilan, persalinan, nifas, KB paska salin, sehingga manfaatnya terbatas dan tidak dimaksudkan untuk melindungi semua masalah kesehatan individu.

\footnotetext{
1 Djamhoermartaadisoebrata, 2005, Kebijakan Pemerintah Dalam Kesehatan Reproduksi Serta Kaitannya Dengan Obstetri Ginekologi Sosial, Bandung, Yayasan Pustaka Sarwono Prawirahardjo

2 Azrul Azwar, 2005, Kebijakan Dan Strategi Nasional Kesehatan Reproduksi Di Indonesia, Jakarta, Bina Kesehatan Masyarakat
} 
Permasalahan yang berkembang adalah kekhawatiran dampak jampersal yang menyebabkan terjadinya ledakan penduduk. Padahal layanan jampersal diharapkan bisa dioptimalkan untuk menekan laju pertambahan penduduk dengan menciptakan sinergi dengan peningkatan program KB pasca salin.

Sayangnya, kewajiban KB pasca salin masih bersifat himbauan karena dalam kebijakan operasional permenkes no.631/menkes/per/III/2011 tidak menyebutkan KB paska persalinan sebagai suatu keharusan sehingga pelaksanaan Jampersal, termasuk KB pasca salin berbedabeda di tingkat Kabupaten / Kota. ${ }^{3}$

Agar terjadi keseragaman pelaksanaan di tingkat Kabupaten/Kota serta meningkatkan pencapaian KB pasca salin maka kebijakan operasional jampersal akhirnya mengalami beberapa perubahan melalui PERMENKES nomor 2562/MenKes/PER/XII/2011 dimana KB pasca persalinan diwajibkan dengan menandatangani surat pernyataan. Kewajiban pelaksanaan KB pasca salin ini menimbulkan pro kontra karena adanya hukum-hukum yang mengatur perlindungan hak-hak reproduksi perempuan.

Hak reproduksi perempuan sebagai bagian dari hak azasi perempuan dijamin pemenuhannya di dalam konstitusi negara Indonesia, sebagaimana diatur dalam Pasal $28 \mathrm{H}$ ayat (1) Undang-Undang Dasar 1945. Ketentuan dalam Undang-Undang Dasar 1945 ini ditegaskan kembali dalam Pasal 49 ayat (3) Undang-Undang No. 39 Tahun 1999 tentang hak azasi manusia yang berbunyi :

Ayat (3): "hak khusus yang melekat pada diri wanita dikarenakan fungsi reproduksinya, dijamin dan dilindungi hukum

Salah satu tonggak sejarah lahirnya kesadaran integratif hak reproduksi yang dihubungkan dengan penanganan masalah kependudukan adalah konferensi Internasional di Kairo, International Conference on Population Development (ICPD). ICPD lebih menyepakati perubahan paradigma baru program KB yang semula menggunakan pendekatan demografis menjadi lebih kearah pendekatan reproduksi dengan memperhatikan hak-hak reproduksi dan kesetaraan gender serta tanggungjawab laki-laki dalam kesehatan reproduksi, termasuk salah satunya KB. ${ }^{4}$

Terkait Undang-undang nomor 36 Tahun 2009 Pasal 72 menyebutkan setiap orang berhak menentukan kehidupan reproduksinya dan bebas dari diskriminasi, paksaan, dan atau kekerasan yang menghormati nilai - nilai luhur yang tidak merendahkan martabat manusia sesuai dengan norma agama. Serta setiap orang berhak menentukan sendiri kapan dan berapa sering ingin bereproduksi sehat secara medis. ${ }^{5}$

Dengan adanya ketentuan dalam PERMENKES Nomor 2562/MENKES/PER/XII/2011 yang mengharuskan bahwa pengguna jampersal wajib untuk ber KB sesudah persalinan sementara dalam prakteknya penerapan permenkes tersebut sulit terlaksana karena kebanyakan pasien tidak mau ber-KB setelah persalinan. Oleh karena itu, penulis ingin melakukan penelitian tentang apa penyebab terjadinya kendala dalam penerapan permenkes tersebut.

\footnotetext{
3 http://MDGs-dev-bps.go.id

4 Hadi Susiarno, 2005, Dalam Hak Reproduksi Perempuan dan Ketidak Adilan Jender, obstetri ginekologi sosial. Bandung, Yayasan Bina Pustaka Sarwono Prawirahardjo.

5 Kitab Undang-Undang Tentang Kesehatan Dan Kedokteran, 2012, Jogjakarta, buku biru
} 


\section{PERUMUSAN MASALAH}

Berdasarkan kepada latar belakang penelitian tersebut, maka penulis mengemukakan beberapa permasalahan :

Bagaimanakah perlindungaan hak reproduksi perempuan dalam mengambil keputusan ber-KB dihubungkan dengan PERMENKES Nomor 2562/menkes/PER/XII/2011?

a. Bagaimana hak reproduksi perempuan apabila ingin mempergunakan jampersal, namun tidak mau ber KB?

b. Apa kendala penerapan PERMENKES Nomor 2562/menkes/PER/XII/2011, dalam hak reproduksi perempuan dalam ber-KB ?

\section{PEMBAHASAN}

Perlindungan terhadap hak reproduksi perempuan telah diatur baik oleh hukum internasional maupun nasional. Hukum internasional CEDAW menyatakan perempuan mempunyai hak untuk perlindungan kesehatan dan keselamatan kerja, termasuk perlindungan fungsi reproduksi. Sementara ICPD di Kairo lebih merinci hak-hak perempuan tersebut berupa hak kebebasan berfikir tentang pelayanan kesehatan reproduksi, hak untuk menentukan jumlah dan jarak kelahiran anak serta hak untuk membangun dan merencanakan keluarga.

Ditilik dari petunjuk teknis Jaminan Persalinan dalam PERMENKES Nomor 631/MenKes/Per/III/2011 yang bertujuan untuk memenuhi kebutuhan jaminan kesehatan Ibu dan bayi baru lahir, pelayanan lebih diutamakan langsung pada penyebab kematian ibu dan bayi baru lahir. Sementara pada Permenkes 2562/Menkes/Per/XII/2011 ditambahkan dengan tujuan meningkatkan akses dan cakupan KB paska persalinan dengan adanya kebijakan operasional pemakaian KB paska salin dengan menandatangani surat pernyataan.

Pelayanan KB paska salin yang tersedia langsung ditujukan pada perempuan sebagai pemanfaat jaminan persalinan sehingga laki-laki atau pasangan perempuan tersebut tidak bisa menggantikan posisi pengguna kontrasepsi (ber-KB). Permenkes ini belum secara terinci menjelaskan persoalan KB sebagai suatu bentuk perlindungan terhadap hak reproduksi perempuan.

Dalam peraturan perundang-undangan yang berlaku di Indonesia, Undang-Undang Nomor 7 tahun 1984 pasal 12 menyebutkan penghapusan diskriminasi dibidang pemeliharaan kesehatan dan jaminan pelayanan kesehatan termasuk pelayanan KB. Terkait Undang-Undang Nomor 39 tahun 1999 Pasal 30 berbunyi:

"Setiap orang berhak atas rasa aman dan tenteram serta perlindungan terhadap ancaman ketakutan untuk berbuat atau tidak berbuat sesuatu".

Perlindungan terhadap kesehatan reproduksi tertuang dalam Undang-Undang Nomor 36 Tahun 2009 tentang kesehatan dan kedokteran Pasal 72 menyatakan setiap orang berhak menjalani kehidupan reproduksi yang sehat dan aman, bebas menentukan sendiri kapan dan berapa sering ingin bereproduksi sehat secara medis dan memperoleh informasi, edukasi dan konseling mengenai kesehatan reproduksi yang benar.

Peraturan perundang-undangan dan hukum-hukum terkait dengan jelas menyatakan perlindungan terhadap hak reproduksi perempuan. Apabila penerima manfaat Jaminan Persalinan didorong untuk mengikuti program KB pasca persalinan (Dengan membuat surat pernyataan), maka tidak ada sinkronisasi antara peraturan perlindungan hak reproduksi perempuan dengan PERMENKES Nomor 2562/MenKes/PER/XII/2011. 
Undang-undang Nomor 36 tahun 2009 pasal 46 menyebutkan:

"Untuk mewujudkan derajat kesehatan yang setinggi-tingginya bagi masyarakat, diselenggarakan upaya kesehatan yang terpadu dan menyeluruh dalam bentuk upaya kesehatan perseorangan dan upaya kesehatan masyarakat".

Penyelenggaraan upaya kesehatan sebagaimana dimaksud termasuk diantaranya kesehatan reproduksi dan keluarga berencana.

Terkait Undang-undang Nomor 36 tahun 2009 pasal 62 ayat (2) berbunyi :

"Pencegahan penyakit merupakan segala bentuk upaya yang dilakukan oleh pemerintah, pemerintah daerah dan atau masyarakat untuk menghindari atau mengurangi resiko, masalah dan dampak buruk akibat penyakit".

Salah satu usaha pemerintah dalam mengurangi kematian ibu dan anak serta sekaligus meningkatkan derajat kesehatan ibu dan anak setinggi-tingginya adalah melalui program jaminan persalinan ini.

Kewajiban pemerintah dalam meningkatkan derajat kesehatan ini seyogyanya tidak melanggar hak reproduksi perempuan sebagai bagian dari hak asasinya. kebijakan ini seharusnya lebih diutamakan pada promosi, perlindungan dan bantuan dalam mewujudkan hak-hak reproduksi serta penyelenggaraan pelayanan, pengaturan dan dukungan untuk keluarga dalam mengatur jumlah, jarak dan usia ideal melahirkan anak serta pengaturan kehamilan.

Karena dalam Pasal 4 (ayat 2) CEDAW menyatakan "Pembuatan peraturan-peraturan khusus oleh negara peserta termasuk peraturan yang dimuat dalam konvensi ini yang ditujukan untuk melindungi kehamilan, tidak dianggap diskriminasi”. Maka, upaya yang dapat dilakukan adalah merinci kembali ketentuan-ketentuan pelaksanaan wajib KB yang bertujuan melindungi kehamilan itu sendiri dimana difokuskan pada kelompok resiko tinggi kehamilan serta meningkatkan kualitas informasi KB dengan cara meningkatkan keterampilan petugas dalam melaksanakan konseling dan komunikasi interpersonal.

Penerapan pelaksanaan KB paska salin berbeda-beda pada tiap daerah. Program jaminan persalinan ini walaupun disebutkan mewajibkan pemanfaat program jaminan persalinan menggunakan KB paska salin namun tidak seluruh daerah menerapkan hal yang sama.

Perempuan yang tidak mau ber-KB setelah persalinan tidak dapat menggunakan Jaminan Persalinan.

Pelaksanaan ini sesuai dengan PERMENKES Nomor 2562/MenKes/PER/XII/2011. Perempuan yang ingin menggunakan jaminan persalinan namun tidak mau ber-KB biasanya dialihkan ke jaminan kesehatan lain yang telah ada sebelumnya atau menjadi pasien umum dengan kewajiban membayar biaya persalinan. Hal ini tidak sinkron dengan Undang-Undang Nomor 36 tahun 2009 Pasal 5 "setiap orang mempunyai hak yang sama dalam memperoleh akses atas sumber daya di bidang kesehatan".

Pada ICPD tahun 1994 juga menjabarkan bahwa hak-hak perempuan yang dilindungi termasuk hak mendapatkan pelayanan dan perlindungan kesehatan serta hak kebebasan berfikir tentang pelayanan kesehatan reproduksi.

Perempuan dapat menggunakan Jaminan Persalinan tanpa ber-KB dengan membuat surat pernyataan penolakan KB paska salin.

Pelaksanaan ini didasarkan pada keadaan dimana perempuan membutuhkan pelayanan persalinan karena resiko kehamilan yang dialami sementara tidak memiliki dana untuk pembayaran jasa pelayanan kesehatan. Pengendalian resiko lebih diutamakan daripada kewajiban pemakaian KB paska salin. Keadaan ini lebih mendekati pada perlindungan terhadap 
hak kebebasan menentukan pemilihan kontrasepsi dan hak untuk dilindungi dari kematian karena kehamilan.

Sesuai dengan pernyataan bahwa "Penghapusan diskriminasi di bidang pemeliharaan kesehatan dan jaminan pelayanan kesehatan termasuk pelayanan KB (UU No.7 Tahun 1984 Pasal 12). Perempuan mendapat kebutuhan pemeliharaan kesehatannya tanpa harus merasa terbebani dengan pelaksanaan KB paska salin.

Setiap hak biasanya disertai dengan kewajiban. Undang-undang Nomor 36 pasal 9 ayat (1) berbunyi "Setiap orang berkewajiban ikut mewujudkan, mempertahankan dan meningkatkan derajat kesehatan masyarakat yang setinggi-tingginya". Kewajiban yang dimaksud tidak dijabarkan lebih lanjut sehingga tidak ada sangsi hukum bagi yang melanggar.

Penggunaan Jaminan persalinan tanpa ikut ber-KB dan tanpa surat pernyataan penolakan KB paska salin sering terjadi pada rumah sakit rujukan, dimana pelaksanaan KB paska salin dikembalikan pada pelayanan tingkat pertama. Hal ini dikarenakan sistem rujukan berjenjang pada penatalaksanaan pelayanan kesehatan ibu hamil ini, memungkinkan menjadi peluang bagi pemanfaat jaminan persalinan untuk menghindari pemakaian KB paska salin dengan memilih rujukan balik ke tingkat pelayanan dasar atau bidan desa.

Disisi lain, sistem pembayaran biaya persalinan dan KB dengan mekanisme klaim secara terpisah menyebabkan tidak ada kerugian pada tingkat pelayanan pertama maupun lanjutan apabila menolong pasien persalinan baik mereka ber-KB atau tidak sehingga perhatian petugas untuk pelaksanaan KB paska salin menjadi kurang.

Penerapan KB paska salin dalam Permenkes Nomor 2562/MenKes/PER/XII/2011 menghadapi beberapa kendala karena adanya otonomi daerah. Kabupaten/Kota menerapkan pelaksanaan yang berbeda sesuai dengan kebutuhan dan kemampuan daerah tersebut sekaligus tenaga kesehatan yang ada serta ragam masyarakat sebagai penerima manfaat jaminan persalinan itu sendiri.

Status sosial, ekonomi dan pendidikan juga berpengaruh secara tidak langsung pada penerapan permenkes ini dimana perempuan perkotaan lebih bisa memutuskan pemilihan KB atau tidak tanpa terganggu dengan adanya penandatangan pernyataan pemakaian KB paska salin dibanding dengan perempuan pedesaan.

Diantara beberapa kendala dalam penerapan Permenkes ini adalah:

Peserta Jaminan Persalinan kurang mendapat informasi dan edukasi yang tepat mengenai KB paska salin pada saat kehamilan terutama trimester terakhir kehamilan. Walaupun pada saat antenatalcare atau pelayanan kehamilan terdapat KIE mengenai KB, namun pelaksanaannya pemanfaat jaminan persalinan baru diminta persetujuan pemakaian KB pada saat setelah melahirkan. Keputusan diambil pada situasi yang tidak menguntungkan, sehingga perempuan tidak dapat memutuskan jenis KB yang akan digunakan setelah persalinan secara alamiah sesuai dengan keinginannya. Hal ini bertentangan dengan Undang-Undang no 39 tahun 1999 Pasal 30 yang berbunyi:

"Setiap orang berhak atas rasa aman dan tenteram serta perlindungan terhadap ancaman ketakutan untuk berbuat atau tidak berbuat sesuatu".

Penyediaan alat kontrasepsi yang tidak siap pakai pada tiap tingkat pelayanan jaminan persalinan memberi peluang kepada pemanfaat jaminan persalinan untuk menghindar dari kewajiban pemakaian KB paska salin. 


\section{KESIMPULAN}

Berdasarkan uraian dari hasil penelitian dan pembahasan terhadap materi yang terkandung dalam tesis ini, maka dalam tesis ini dapat disimpulkan sebagai berikut:

1. Perlindungan terhadap hak reproduksi perempuan dalam mengambil keputusan ber-KB bertentangan dengan PERMENKES Nomor 2562/MenKes/PER/XII/2011 yang menyatakan kewajiban pemakaian KB paska salin dengan menandatangani surat pernyataan. Akan tetapi Pelanggaran hak reproduksi pada pengguna KB dapat saja dilakukan sepanjang kepentingan kemaslahatan (kesejahteraan, kebahagiaan, kebaikan, keamanan dan ketertiban) pada pasien resiko tinggi.

2. Hak reproduksi perempuan tidak dapat dipenuhi apabila ingin mempergunakan jampersal namun tidak mau ber-KB.

3. Kendala penerapan PERMENKES Nomor 2562/MenKes/PER/2011 dalam pemenuhan hak reproduksi perempuan dalam ber-KB adalah keputusan pemilihan KB baru ada setelah adanya persalinan, tidak tersedianya alat kontrasepsi siap pakai pada tiap tingkat pelayanan jaminan persalinan, dan komunikasi, informasi dan edukasi yang kurang efektif mengenai KB paska salin.

\section{SARAN}

Berdasarkan uraian mengenai perlindungan hak reproduksi perempuan untuk ber-KB, maka dalam penelitian tesis ini, yang dapat disarankan kepada Kementerian Kesehatan sebagai pembuat kebijakan, Dinas Kesehatan Kabupaten/Kota sebagai Tim Pengelola dan tenaga kesehatan sebagai pelaksana pelayanan jaminan persalinan, agar kebijakan mengenai KB paska salin ini dapat menjadi lebih baik lagi dan melindungi semua pihak dari segi hukum, maka beberapa alternatif yang dapat dilakukan adalah sebagai berikut:

1. Kementerian Kesehatan

Melakukan penambahan pada kebijakan operasional tentang pelaksanaan kewajiban KB paska salin pada kriteria resiko tinggi kehamilan dengan tujuan menurunkan angka kematian dan angka kesakitan pada ibu hamil.

Penandatanganan surat pernyataan pemakaian KB dilakukan saat kunjungan pada trimester terakhir kehamilan setelah ibu hamil mendapat informasi yang lengkap mengenai kondisi kesehatan dan jenis KB yang akan digunakan sehingga perempuan dapat memutuskan sendiri untuk ber-KB.

Pelaksanaan pengklaiman jasa pelayanan Jaminan Persalinan sebagai satu kesatuan termasuk pelayanan KB paska salin.

2. Dinas Kesehatan Kabupaten/Kota

Dinas Kesehatan selaku Tim Pengelola Kabupaten/Kota meningkatkan koordinasi dengan penanggung jawab institusi fasilitas kesehatan pemerintah dan swasta dengan mengatur hak dan kewajiban para pihak dalam jaminan persalinan serta SKPD Kabupaten/Kota yang menangani program keluarga berencana serta BKKBN Provinsi.

3. Tenaga kesehatan

Memberikan Komunikasi, Informasi dan Edukasi efektif mengenai KB pada saat kunjungan terutama trimester terakhir kehamilan sekaligus meminta persetujuan jenis KB yang akan digunakan.

Membuat pencatatan dan pelaporan yang riil mengenai Jaminan Persalinan dan pemakaian KB paska salin sehingga alat kontrasepsi tersedia dan siap pakai. 


\section{DAFTAR PUSTAKA}

Achie S. Luhulima, 2007, CEDAW Mengembalikan Hak-Hak Perempuan, SMK Grafika Desa Putera, Jakarta

Adhi Santika,2007, laporan pengkajian hukum Tentang Optional protocol cedaw terhadap hukum nasional yang berdampak pada pemberdayaan perempuan, Jakarta

Adnan BuyungNasution, 1997, InstrumenInternasionalpokokHakAsasiManusia, YayasanObor Indonesia

Agnes widanti, 2005, Hukum Berkeadilan Gender Jakarta Buku Kompas

Agnes Widanti, dkk, 2009, Petunjuk Penulisan Usulan Penelitian dan Tesis, Penerbit Universitas Katolik Soegijapranata, Semarang

Agus Siswanto Wilopo, 2001 Kumpulan Pedoman Pelaksanaan Program Kesehatan Reproduksi Remaja dan perlindungan hak hak Reproduksi, Jakarta, BKKBN Direktorat Remaja dan perlindungan hak hak Reproduksi.

Andrei Ramani, 2011, Pelaksanaan KB (melalui jampersal) untuk menekan laju pertumbuhan Penduduk dan pencapaian target millenium development goal (mdgs), Jember, 1Departemen Epidemiologi, Biostatistika, dan Kependudukan, Fakultas Kesehatan Masyarakat,Universitas Jember

Ari Sulistyawati, 2011, Pelayanan Keluarga Berencana, Jakarta, Salemba

Aryani, 2002; Pusat Studi Wanita Universitas Udayana, 2003; Sudarta, 2005).

Azrul Azwar, 2005, Kebijakan Dan Strategi Nasional Kesehatan Reproduksi Di Indonesia, Jakarta, Bina Kesehatan Masyarakat.

Azrul Azwar, 2008, Program Kesehatan Reproduksi Dan Pelayanan Integrative Di Tingkat Pelayanan Dasar, Jakarta. , Bina Kesehatan Masyarakat.

Bappenas,2002, Analisa Gender dalam Pembangunan Keluarga Berencana Nasional, Jakarta

Bappenas, 2010, Ringkasan Peta Jalan Percepatan Pencapain Pembangunan Milenium Di Indonesia, Jakarta.

Buku Pedoman Lapangasn Antar-lembaga Kesehatan Reproduksi dalam Situasi Darurat Bencana, 2010

Dharma S, 2006, Konsep dan Teknik Penelitian Gender, Malang, UMM Press

Djamhoer Martaaddisoebrata, 2005, Etika Klinik Dalam Obstetri Ginekelogi, Bandung, Yayasan Pustaka Sarwono Prawirahardjo

Djamhoer martaadisoebrata, 2005, Kebijakan Pemerintah Dalam Kesehatan Reproduksi Serta Kaitannya Dengan Obstetri Ginekologi Sosial, Bandung, Yayasan Pustaka Sarwono Prawirahardjo

Djamhoer martaadisoebrata, 2005, Perkembangan Obstetri Ginekologi Sosial, Bandung, yayasan bina pustaka sarwono prawirahardjo.

Gilly Andrews, Buku Ajar Kesehatan Reproduksi Wanita (edisi 2), Jakarta, EGC

Hadi Susiarno, 2005, Dalam Hak Reproduksi Perempuan dan Ketidak Adilan Jender, obstetri ginekologi sosial. Bandung, Yayasan Bina Pustaka Sarwono Prawirahardjo.

Ida Ayu Chandranita Manuaba. et. al, 2009, Memahami Kesehatan Reproduksi Wanita. Jakarta, EGC. 
Intan kuamalasari, 2012, Kesehatan Reproduksi,Jakarta, Salemba Medika

Israwati, et. al, 2005, Keluarga Berencana, Kesehatan Reproduksi, Gender Dan Pembangunan Kependudukan, Jakarta, BKKBN dan UNFPA.

J.B. Daliyo, SH, 2001, Pengantar Ilmu Hukum. Jakarta, PT Prenhallindo.

Jusuf Hanafiah, 2012, Etika Kedokteran Dan Hukum Kesehatan, edisi IV, Jakarta, EGC.

Kementrian Kesehatan Republik Indonesia, 2011, Buku Saku Jampersal, Jakarta, pusat Promosi Kesehatan

Kitab Undang-Undang Tentang Kesehatan Dan Kedokteran, 2012, Jogjakarta, buku biru

Permenkes No 631/Menkes/Per/III/2011

Permenkes no. 2562/MENKES/PER/XII/2011

Pranoto Iskandar, 2010, Hukum Hak Asasi Manusia Internasional, Perpustakaan Nasional Indonesia

Pusat Humaniora, Kebijakan Kesehatan Dan Pemberdayaan Masyarakat Pelayanan keluarga berecana pasca persalinan Direktorat Bina Kesehatan Ibu Ditjen Bina Gizi dan Kesehatan Ibu dan Anak, Kementerian Kesehatan RI

Ratna Suprapti Samil, 2001, Etika Kedokteran Indonesia, Jakarta, yayasan bina pustaka sarwono prawirohardjo.

Rea Abada Chiongsong, 2010, Apakah Hukum kita Meningkatkan Kesehatan Gender? Buku Pegangan Untuk Tujuan hokum Berbasis CEDAW. Bangkok Thailand. ASIA Regional Office

Soekidjo Notoatmojo,2010,Etika dan Hukum Kesehatan,Jakarta,Rineka

Soerjono Soekanto, 2001, Penelitian Hukum Normatif, Jakarta, PT RajaGrafindo Persada

Sriwiyanti Eddyono, 2004 Hak Asasi Perempuan dan Konvensi CEDAW, Jakarta, Lembaga Studi dan Advokasi Masyarakat

Sumiarni, E dan Tangkilis, 2004, Gender dan Feminisme, Yogyakarta, Publishing Company

Syahmida S.Arsyad.Et al,2005,Promosi Pengarusutamaan Gender, Buku Sumber untuk Advokasi,Jakarta, BKKBN

Tety rachmawaty, Et al,2013, Riset Evaluasi Jampersal, Surabaya, Kementerian Kesehatan RI Badan Penelitian Dan Pengembangan Kesehatan

Todung Mulya Lubis, 2004, Jalan Panjang Hak Asasi Manusia, Jakarta, PT Gramedia Pustaka Utama

Wening Udasmoro, 2004, Konsep Nasionalisme dan Hak Reproduksi Perempuan, humania vol 16 Wibisono, 2003, Menggapai Keluarga Bahagia, Lumajang, Lembaga Kajian As-Sakinah

Widyastuti, 2009, Kesehatan Reproduksi, Yogyakarta, Fitramaya

http://dinkes.banyuwangikab.go.id/12-laporan-khusus/32-kesehatan-reproduksi-mengikutikeluarga-berencana.html

http://MDGs-dev-bps.go.id

http://biologimediacenter.com/sistem-reproduksi2-reproduksi-pada-manusia

http://id.wikipedia.org/wiki/hereditas

www.ibudanbalita.net/1096/metode-kontrasepsi.html 